\title{
Social Construct of Precariousness among the Refugees in the General Hospice of Geneva
}

\author{
Timothée Codjo TOGBE \\ Université d'Abomey-Calavi, Faculté des Sciences Humaines et Sociales, Département de Sociologie- \\ Anthropologie
}

\begin{abstract}
The Refugees' living conditions in Europe is triggering nowadays various scientific perspectives and analyses. This article which follows a sociological perspective analyzes some social determinants which structure the precariousness among Refugees in Geneva. Investigations have been carried out along the line of qualitative research method paradigm. Thus, the life story, the semi-structured interview and direct observation using tools such as the interview guide and observation grid have been used in the process. Following the purposeful systematic sampling technique along with the diversification of research areas, 10 actors were approached. The collected data have been processed through content analysis and data triangulation. The theories used are those of the social gradient, misery induced by position, and resilience. It can be inferred from the findings that the legal status of refugees - the type of residence permit and the status of "People without papers" - significantly contributes to the social construct of their precariousness. All the same, a close examination shows the uncertainties related to any successful professional socialization once back in the country of origin, and the fear of being stigmatized as the symbol of patent failure. Those realities coerce the refugees prefer the misery imposed by their living conditions rather than returning home. By way of conclusion, they think it is useless returning home as long as one has not succeeded.
\end{abstract}

Keywords: Social Construct of Precariousness, Legal Status, Acceptance of Precariousness, Geneva.

\section{INTRODUCTION}

In Geneva, the organization of reception of asylum seekers goes through several structures including the General Hospital, the Refugee Care and Support Unit in Petit-Saconnex- a district in Geneva citylocated on the right bank of Geneva Lake which lies between the Intercontinental Hotel and the PetitSaconnex Cemetry (see map attached). This institution takes care of people in difficult situations including refugees from the support unit of the Petit-Saconnex Center. It operates as a Social Assistance Unit. According to the Republic and the Geneva District (2008), this Geneva-based Social Assistance Institution is assigned among other missions, to guarantee minimum conditions and livelihood for the beneficiaries, to develop and maintain ability for independence by mobilizing the individual's equity resources, urging and helping the target person to become autonomous and by supporting him/her to integrate the host country. The French Refugees and Stateless Persons Protection Office (OFPRA) plays relatively similar role in France as Bierset does in Belgium in the reception of refugees. It could be theoretically said that there is a desire to socialize and integrate refugees with a view to facilitating their lives through social assistance. However, it can be noted the existence of a gap between the discourses produced regarding social assistance given to this social category and the tangible reality. In fact, asylum seekers live in a situation of poverty and lack of integration which are not voiced in the speeches. M. Togni (2009: 1) contends that incongruity by stating that:

Poverty is a reality which Geneva always struggles to perceive. Discreet, if not hidden, it does exist in the canton of the lake bank. And the General Hospice has been a privileged observatory for almost the past five centuries, as an instrument created to cope with it. 
In fact, the refugees enjoying assistance sometimes are in a situation qualified as "misery of position" (P. Bourdieu: 1995), that is to say, the vertical suffering or more exactly the feeling of being drawn towards the bottom. Clearly speaking, their legitimate aspirations to happiness come across some constraints forcing them to stay at the bottom of the ladder. This means that they find themselves partitioned into a social position of inferiority. The Geneva policy does not necessarily fit into the logic of improving their living conditions. A Swiss politician protests against this situation as follows:

«Asylum-seekers receive only miserable assistance (overnight stays in a civil protection center good for two meals a day) which does not allow for living in dignity at all. Worse, the threat of depriving them of this emergency aid is constantly agitated to coerce them to declare themselves voluntary to return to the country they had to flee. In practice, they are pushed into hiding and some of them indulge in a delinquency of survival. [...] Recently, a large number of them, perfectly autonomous, were forced to leave their jobs and return to the assistance [...] » (P. Weiss, 2004: 12).

This statement shows that refugees go through difficult life trajectories in their countries of destination/asylum. They are sometimes intimidated because they are regarded by the host communities as different people. However, international standards and instruments such as the "1951 Convention" and the "1967 Protocol" relating to the status of refugees (UNHCR and IPU, 2001) call for better protection and support to these vulnerable groups with a view to rebuilding a decent life. Most of the time, the dream nurturing and energizing refugees' determination to cut themselves off from their homeland to Europe, comes across some realities that are contrary to what they had hoped to flee in their home countries. And yet, few of them are ready to return home despite the daily deterioration of their living conditions and existence. Understand this situation goes through answering the following question: What does substantiate the Refugees' stubbornness to remain in exile despite the daily deterioration of their position of misery in their host community?

\section{Methodology AND TheORETICAL FrameWork}

\subsection{Methodological Approach}

This article is premised on capitalizing some research works undertaken in the Geneva Graduate Institute of International and Development Studies (IHEID) in 2011 as part of our academic activities. It has been absolutely important to apply the "Qualitative field approaches (E713)" through the choice of a subject to matter to be investigated in the field. This is how the Geneva General Hospice has been chosen as a research area. In order to cast wide and deepen its analysis on the refugees' precariousness, this study has, in addition to the Geneva General Hospice, carried out investigations in Belgium and France during the summers of 2015, 2016 and 2017. This approach has allowed not only to triangulate the collected data, but especially to generate information on the refugees' experiences.

The qualitative approach adopted for this survey has allowed to analyzing the refugees' subjective experiences and trajectories. In this investigation process, the life story, semi-structured interview and direct observation have been used. The tools used in relation to these research techniques are respectively interview guide and observation grid. Using the technique of rational choice and the diversification of research areas, ten (10) actors are approached, namely 08 refugees among whom 05 are at the Geneva General Hospice, 02 in Belgium (Gare Guillemin), 01 in France (Porte de la Chapelle) and 2 agents of the institutions in charge of Refugees' protection (01 from OFPRA in France and 01 from the General Hospice in Switzerland). Refugees were chosen according to their legal status (without residence permit, residence permit $\mathrm{F}$ and $\mathrm{N}$ ). Content analysis and data triangulation are the methods used for data processing.

\subsection{Theoretical Framework and Concepts}

This research is part of the sociology of precariousness developed by B. Maryse (2007) which aims to analyze the processes of casualization. Flowing along with the author's dynamic of accounting for the 
determinants that structure the refugees' precariousness, the theory of "social gradient" (closing the gap) and "misery of position" applies. The first, developed by M. Marmot et al. (2008) shows that the more the refugees' status becomes fragile, the worse their living conditions deteriorate. The second, developed by P. Bourdieu (1995), complements the first because it highlights that refugees will suffer more when they are kept at the bottom of the scale. In order to avoid falling into the trap of refugees' victimization which would challenge their capacity for action, limit the level of analysis and the deconstruction of the subject matter of this study, the theory of resilience put forward by S. Vanistendael (2009) for the analysis of difficult childhood has been used. This author mentions:

\begin{abstract}
"Human resilience is above all a reality that we can observe: life paths that surprise us for good. We certainly know a family member, a friend, a neighbor or a colleague who experiences a very difficult life but who is positive, smiling, committed, without any pretensions. Resilience is the ability of an individual or group to overcome very big challenges and to grow in life. It may be trauma, extreme poverty, serious illness, heavy bereavement, [poor living conditions], or other problems. The growth of resilience will often be through ups and downs. Beyond the resistance, it is the ability to rebuild life, and sometimes even to turn a misfortune into something positive.
\end{abstract}

[...] Resilience is neither a magic solution to problems, nor a substitute for economic and social policy, but rather a means for growth which mobilizes the resources of a person and his environment. Some elements often seem to contribute to resilience: to feel fundamentally accepted by another person without necessarily implying any behavioral endorsement - this element is often considered the most important - the discovery of a positive meaning to one's life, benchmarks, the feeling of having a certain hold on one's life, a positive self-image without illusions, a series of social or other skills, a sense of constructive humor, etc. [...] Resilience is not a technique of intervention, but it inspires another view which, while recognizing problems, seeks beyond resources and positive elements, even modest ones, that will help rebuilding life [...]» (S. Vanistendael, 2009: 10-11).

The theory of resilience is appropriate for this research as it will allow to appraising how refugees manage to get out of precariousness so as to build a stable life. It is therefore not a matter of painting the slade in black for all refugees, even though we know that most of them are suffering in their trajectories, but to see if some people manage to succeed in lives.

\title{
3. Scientific Debates on the Refugees' Precariousness
}

From a definitional point of view, B. Maryse (2007) distinguishes two meanings of the term "precariousness": either it rather means the poor populations who can even be excluded when housing problems arise in addition; this refers to people at risk of seeing their situation deteriorate. Overall, uncertainty about the future is a decisive factor induced by the very concept of precariousness.

There are many writings evidencing that precariousness exists in Geneva and is part of the refugees' daily life. This is what M. Togni (2009) alludes by mentioning that precariousness « [...] does indeed exist in the canton of the end of the lake. And the General Hospice is a privileged observatory [...] ». In the same vein, P. Weiss (2004) points out that «Refugees are in a precarious situation. [...] In practice, they are pushed underground and some of them switch to delinquency of survival ». We could deduce from this statement that asylum seekers face pressure from the host country through the legal system. In other words, the poor positions of the latter depend on their legal status. This analysis goes in the same vein with that of C. Bolzman (2001: 136) which indicates that:

«The legal status that refugees will be granted or denied will strongly influence their chances of having a place in the society of destination, or of being immediately excluded from it; it will also weigh on the possibilities they will have to access the labor market and the social protection system under the same conditions as nationals. Legal status - 
or the absence of it, whether present or planned - is therefore a cornerstone of integration or precariousness, or even exclusion. In Switzerland, the social trajectories of asylum seekers are currently strongly predetermined by restrictive asylum policies ».

Restrictive asylum policies mean that the host country of the asylum seekers does not give the latter all rights. L. Parini (1997) has pinpointed four major aims going along with those measures: deter (through a series of restrictions on the right to work, freedom of establishment, the candidate's hearing, the chances of obtaining a positive response) (1), fast track the procedures (2), avoid applicants' integration (3), ensure the enforcement of the decisions, in particular expulsion (4).

From these analyzes, it can be inferred that everything is being done to keep refugees in a difficult situation. Criticizing the law on asylum based on the practices going along with it, R. Metzler and C. Blocher (2004) writes: "Those who do not collaborate shall not be given food. This calls for the amendment of the asylum law. Our asylum law is no longer valid as long as refugees no longer benefit from its protection $»$. Considering the authors' standpoint on the precariousness of refugees, it can be argued that asylum seekers are legally vulnerable and are exposed to expulsion at the slightest chance or false step. Therefore, one could say that they survive the informal sphere of lawlessness and experience a paradoxical situation that Schwab (2000) describes as "non-integrated integration", developing a real "ethos of resourcefulness". (P. Grell, 1987).

Contrary to the previous authors' analysis, some authors have addressed the issue of precariousness through labour. Specifically, they have not emphasized the refugees. But, their work is illustrative. For R. Castel (1995), the transformation of the wage society complicates more the labour-based integration and weakens some social networks, rendering individuals more vulnerable. It can be understood from this assertion that some social categories, including refugees, can remain vulnerable even while working. Still in a view to establishing connection between work and precariousness, M. Lewerer and C. Dunand (2001: 10) note that:

"Working conditions in the wage-earning sector are increasingly precarious (short-term contracts, increased demands from employers, increasing stress, etc.) and wage differentials strongly increase [...] poorly paid jobs, very low income which will never result in reemergence of the very marginal social category: the working poor [...] ».

That is to say, there is a network of workers that could be regarded as "precarious workers". As far as precariousness is concerned, P. Bourdieu (1995) speaks in terms of "vertical suffering" meaning that there is on the labor market, within the same category of the same group, a top-down mechanism to keep a group of people at the bottom of the ladder. Additionally those works by various researchers have addressed the issue of insecurity and contributed to broadening our view on the subject, especially on the reasons drowning the refugees in this situation.

\section{Findings AND Discussion}

The legal status of refugees and the perception themselves have about their situation have all been tapped into on purpose of these findings discussion.

\subsection{Refugees' Legal Status As A Cause of their Precariousness}

\section{a) Refugees without Resident Permit And Precariousness}

Based on the data collected on the ground, it is highlighted in this section that the refugees' legal status could contribute to their retention in precarious situation. In fact, this status stems from the type of residence permit issued by the Cantonal Population Office (OCP) of Geneva as well as in Belgium and France. The General Hospice hosting asylum seekers does not have any margin of maneuver with regard to their residence permits. The refugee applies to the Cantonal Office to obtain a residence permit. And, that can be accepted or rejected. Three categories of refugees could be distinguished: those who have the F permit, those who have the $\mathrm{N}$ permit and those who are without a residence permit. The first two categories are more or less protected compared to refugees who are yet to get a residence permit. In other words, Geneva State recognizes them legally unlike the others "paperless". The latter suffer more than those who have them. This suffering appears through the treatment they 
receive from support agencies that are supposed to assist them, the politico-administrative authorities, the populations, etc. The following speech by an interlocutor confirms this analysis:

"Life abroad, "life adventure" We cannot have more place here than in our homeland. We have no strength in Europe. We do not have much capacity. What I was expecting before coming here is over. In Europe, I have no more dreams. I do not dream of having anything anymore. At the time, all I'm looking for is to defend myself to have something to eat ... bread in the morning ... bread in the afternoon ... that's all ... that is all I'm looking for now. I am now coerced to do what I did not want to do before. No human being is wicked at birth. Only the environment turns him into a criminal. In a word, the environment transforms the man. If you are in an environment where people live well and treat you well, you will be a good man too. Here, for instance, the man is threatened and he has no relative to defend him. I do not have anyone here who can be of assistance to me I do not have someone like a social worker who helps me. I am in a self-guidance. Last time, I went to the cantonal hospital to be treated for an injury but they required my residence permit. It was vexed. The injury was so painful that I could not sleep in the night. I went to receive a treatment, and in return they told me that if I do not have a permanent address, it can't bet possible. They abandoned me and attended to those who have paper. According to the health workers, I am not a man. I do not deserve to live. We use to talk about human rights here but I could not see any evidence of that. I was so much discouraged that day. I was so shocked by what their behavior. We do not have a decent life here being a Black, there are restaurants here where you cannot go. I do not even think about working because it's impossible. I do not have paper. All we are looking for is just something which can stand as the daily bread. I have a white friend of mine who gives Black people jobs in his house. I work at home for twelve hours and he pays me a little money. I prefer that instead of having another problem. Here, those are the kind of people prompting others to stand and sell drugs along the road side. If you sell along the road side and the police arrests you, you are thrown in jailor returned back to any country. There are a lot of people here selling drugs. They do that job unwillingly just to meet their daily sustenance. I cannot live that life forever. My life must change. But, how does it change? There is no hope here. Everything starts here by permanent address, but I do not have any. I was chased from the country. I came here by boat. I crossed Atlantic Ocean in two weeks. I have been praying that God to protect me so that I do not lose my life in the ocean, because I was expecting a better life in Europe. I thought there were light ahead but rather some darkness. The light is left behind in my homeland. I should negotiate and stay there. Africa is better for me. All my current concern is how to get back home. If I stay here I cannot gain anything. Always, there is the spectrum of prison, always, always. If you are here today you are here, tomorrow you are in prison. It's difficult. We were not born for living the life of prison for ever »(Guinean refugee without a residence permit, Hospice General, Geneva, January 20, 2011).

The statements made by this interlocutor show that he was happy to leave his country to take refuge in Geneva, Switzerland, a country where his dreams should come true. But, his status paperless refugee has been become a serious handicap on his way to achieving his expectations. He can barely eat, but he accepts it like that. He cannot go to the health center for treatment because of his status; he can't even enjoy himself, etc. Being without resident permit significantly reduces the importance that host country authorities should show for refugees. This does not mean that those who hold a residence permit are de facto integrated in the host country. However, the residence permit allows the holder to 
enjoy a relative peace of mind and start building a life compared to those who are, to some extent, coerced to be at the bottom of the ladder. This analysis is part of the social gradient theory (M. Marmot et al., 2008) and that of misery of position (P. Bourdieu, 1995) which shows that the lower the social position, the less and the lower the probability to fall sick and die is great. Applied in the context of this research, we can easily say that if the (paperless) status of refugees is not allowed in their host country, they will suffer more because they will not have easy access to basic social services. In this condition, they run the risk of being maintained and drowning in precariousness. This statement by an informant illustrates this reflection:

\begin{abstract}
" [...] we are ill-treated. The poop of a dog here in Geneva is has more value than the life of refugees. According to me, precariousness is not strong enough. Let's talk about exclusion and marginalization. The system transforms us into drugs dealers and coerces us to become members of the Pâquis networks. Our situation is unstable. It is not easy. We are not recognized $»$ (Refugee without a Residence Permit according to Hospice General, Geneva, February 22, 2011).
\end{abstract}

The information gathered from the different socio-categories shows that the refugees' precariousness is due to their legal status. This analysis is confirmed by the statement according to which " the legal status that refugees will be granted or denied will strongly influence their chances to secure a position in the country of destination [...] » (C. Bolzman, 2001: 136). This means that the refugees' living conditions depend on getting residence permit, a legal document that gives asylum seekers the opportunity to build a future

\title{
b) Is Resident Permit an Exit from Refugees' Precariousness?
}

A priori, the obtaining of the residence permit should constitute a way out to the refugees' precariousness since this document gives them an identity and a legitimacy which allow them to be recognized and accepted by the institutions of the country of destination. But examined critically, closely and deeply, it is not enough to hold a refugee residence permit and de facto get out of the vicious circle of precariousness. To elucidate this idea it would be advised to start analyzing two types of residence permit often issued to refugees in Geneva and the related uses. These are residence permits $\mathrm{N}$ and $\mathrm{F}$. The residence permit $\mathrm{N}$ gives refugees the possibility to stay in the asylum territory, to receive training if such opportunity arises and to enjoy social assistance. With this residence permit, refugees can benefit from assistance in terms of food, clothing, healthcare, common housing in a reception center, etc. Therefore, this document keeps them in a position of dependence along with a lifestyle relegated to the strict minimum offered by the authorities in the host country. As a matter of fact, this does not allow them to live with dignity as pointed out by P. Weiss (2004: 12): «...asylum seekers just receive only a miserable assistance (overnight stays in a civil protection shelter, good for two meals a day) which makes it impossible to live in dignity at all [...] ». Through Residence Permit $\mathrm{N}$ which prevents them from working officially, meeting their own needs and live decently and autonomously, the refugees are indirectly pushed to begging, moonlighting, prostitution, theft, drugs sale, etc. Those are survival or resourcefulness strategies. In other words, they engage in activities that they could have avoided. This is what the following informant states: "Life is hard abroad. We have to sell drugs, to prostitute ourselves. We have no choice because we have to eat. Our comrades holding Residence Permit $F$ are better than us "(Refugee with a Residence Permit N, General Hospital Geneva, February 24, 2011). These statements clearly show that Residence Permit N contributes to design and shape refugees' precariousness. Clearly, instead of taking them out of their precarious situation, they are gotten bogged down though they are granted a so-called legitimacy compared to those who do not have. Unlike Residence Permit N, the F category could be regarded as a way out of the refugees' precariousness because this document authorizes them to work officially. In other words, this paper gives refugees possibility to get out of aid, to earn a salary, meet their own needs independently and build their own lives. The work permit gives refugees opportunity to get a job, even if it is not easy, to live a relatively decent life in their host country. A refugee confirms this analysis as follows: 
"I came here in Liege (Belgium) as a refugee in 2011. I firstly thought things would be easier for me. But that is not the case. The day I was taken to the Bierset Welcome Center, it was as if I were being taken in jail. This is where all the refugees are received. I spent eight (08) months in this center. Thanks to God, they allowed me to do some training. I graduated in pastry and bakery. Following this, I obtained my residence permit to work. Thanks to this paper, I got a job in category 4; which allows me to earn 2100 Euros per month. I brought my wife and children. I have my car. It's okay. It must be said that there are people who have been here for ten (10) years and who have not managed to get the papers. If you do not have the papers here you are nothing. You cannot build your life. I brought my family. I am happy »(Togolese refugee, Liège, Herstal district, August 20, 2016).

This refugee shows that his life was not easy during his first days in Belgium. But, thanks to the help of his reception center, he has been able to receive a training at the end of which he obtained the work permit; which has facilitated access to a job through which he flourishes. That is to say that he has somehow left precariousness (period before work permit) for a relatively happy life (period after work permit) as indicated by the theory of resilience, namely, that man has had « [...] life trajectories that surprised everyone with the [...] the capacity ... to overcome very great difficulties and to grow in life [...]» (S. Vanistendael, 2009: 10). The host country has, in this case, recognized the problems of this refugee (whose training) and helped him to rebuild his life. This resilience has been successful because the refugee did not content himself with the accompaniment given by the host organization in Belgium (Bierset) but was determined to move forward, so he has posited his future despite his suffering at the beginning of this journey for survival as he mentioned in his statement: The legal status of refugees and more specifically the work permit can help get them out of precariousness. However, it is worth noting that having work permit is not a panacea leading automatically to the job that can help build a decent life (renting a home, having fun, etc.). Having this residence permit is good, but struggling to get a job is better. Nowadays, Gender imbalance at workplace is a virtually striking reality irrespective of continents, social and socio-professional categories. In such a context, refugees having their residence permit which allows them work are bound to cope with the job offered to them. This paper is not going about the categorization associating job typologies to refugees in order to avoid any biased analysis and objectification of precariousness in the job market. Some citizens may have precarious employment though they are in their own homeland. Therefore, job precariousness has nothing to do with refugee status. In other words, it would not be because one is a refugee that $\mathrm{S} / \mathrm{he}$ would have precarious employment or a job worsening precariousness instead of helping to get the way out to the vicious circle. Because of the social paradigms shift those trades which were in the past reserved for men of color, that is to say blacks are nowadays discussed by Europeans. For instance, it is not uncommon to see a bakery and pastry service in Europe, a refugee and a white man occupying the same positions as refugees and Europeans working in a maintenance unit. It is true that the work can consolidate precariousness, but failing to demonstrate that aspect here would prompt to admit that access to a job is a sine qua non condition for a refugee to improve living conditions. It is difficult for refugees who have no papers or a residence permit that hampers access to work, hindering therefore any decent life in their country of asylum. Paradoxically, some of them prefer this life rather than going back to their home country.

\subsection{A Miserable Life Is Better than A Return into A Life of Uncertainty}

According to some of the respondents approached as part of this research, refugees seriously suffer. But some among them prefer this life rather than going back to their country of origin. Those are, in fact, people who have definitely lost hope about any normal life when they will have returned to their respective countries. They imagine that they would have to face a more miserable life while back into their homeland. That prompts them to accept their precarious living conditions and enjoy themselves. An Officer based at the Refugees Protection Agency confirms this analysis through the statement which follows:

"Refugees who come and live in France suffer in my opinion. They sleep under bridges but use to say that they prefer this condition rather than going back to their homeland. I work with refugees from 
Asia, Pakistan and Congo. Some cannot go back home because they are indebted. Many of them have gotten some loans before coming here in France »(OFPRA agent, Paris, 05 August 2016).

The words uttered by this interlocutor clearly show that some refugees have accepted their experiences and do not plan to return home. The life they lead in their country of asylum is, according to them, normal while those who perceive them from outside think that they rather live an abnormal and pathological life. Therefore, they have rationalities which cannot be decoded unless one approaches, listening to them and following their trajectory from the standpoint of an insider. Before landing in the country of asylum, some had contracted huge debts and had nurtured the hope to work in order to raise money in the host country and reimburse their debts. But the reality they face keeps them in a position of survival for life to the extent of wondering if they could one day return back home. They prefer to stay in an asylum to avoid being arrested and imprisoned upon their return and, as a result, experience shame. That is why, even if the host countries send them back, they oppose resistance to return as it is pointed out in this statement:

\section{"Refugees were sent back to Paris or elsewhere in the reception centers. They stayed there one night and reapplied to Calais. We saw them again along the roads and in the public garden, they slept in the rain, they were dozens homeless wandering, without resources but clinging to asylum countries without papers, without anything » (UNHCR, 2015: 21-22).}

The Refugees' logic consisting in accepting and enduring their difficult living conditions in their country of asylum contributes to maintaining and even worsening their precariousness. This is an option of a randomized life. The fact of being confined in this vicious circle will not give them opportunity to think about escaping and trying to build another life. On the contrary they run a high risk of indulging and engaging in begging, theft, prostitution, etc.

\section{Conclusion}

The Refugees' precariousness is a reality in Europe, and more specifically in Geneva, despite the international standards in force and those institutions protecting vulnerable people. This precariousness, according to empirical data analysis is, on the one hand, due to the refusal of the politico-administrative authorities in the host country to issue a residence permit to this social category of people, creating therefore some "paperless" and, on the other hand, the type of residence permit granted on purpose of legitimizing a legal status. A refugee may therefore have a legal status, that is to say a residence permit and continue to live in a precarious situation because maintained in a position of structured dependence. When the residence permit issued includes the right to work, the refugee, through his job, can begin to re-build his life, strive for his autonomy, self-assertion and live outside the vicious circle of precariousness. But when the issued and granted residence permit does not include the right to work, the beneficiary refugees shall live with the bare minimum granted to them by the reception centers and are, one way or the other, directly or indirectly coerced to live a miserable life. Because of this situation (living on social assistance only), some refugees develop strategies to join some social networks most "members" of which engage in begging, the drugs sales, prostitution and moonlighting. Belonging to these organized networks dominated by leaders who already have a base, sometimes leads some refugees to accept precariousness with the hope a probable success one day. But is the acceptance of this personal experience not a gateway or no-return door as far as precariousness is concerned?

\section{REFERENCES}

[1] Bolzan Claudio, 2001, "Politiques d'asile et trajectoires sociales des refugiés : une exclusion programmée : les cas de la Suisse", In Sociologie et sociétés, vol.33, p.133-158.

[2] Bourdieu Pierre, 1995, La misère du monde, Paris, Seuil.

[3] Castel Robert, 1995, Les métamorphoses de la question sociale, Paris, Fayard.

[4] Grell Paul, 1987, "Pour une stratégie de recherche sur la question du chômage : recherche s'appuyant sur des récits de vie des chômeurs de Montréal", In C. Lalive d'Epinay et R. Sue (dir.), Chômage, marginalité, créativité, Université de Genève.

[5] HCR et UIP, 2001, Protection des réfugiés : Guide sur le droit international relatif aux réfugiés, $n^{\circ} 2$. 
[6] Lewerer Mathieu, Dunand Christophe, 2001, Précarité et exclusion à Genève : une face cachée de la Suisse, Genève, IUED.

[7] Marmot Micheal, Friel S., Bell R., Houweling T.A. et Taylor S., 2008, "Closing the gap in a generation: health equity through action on the social determinant of health".In.The Lancet, vol 372, p.1661-69.

[8] Maryse Bresson, 2007, Sociologie de la précarité, Paris, Armand Colin.

[9] Metzler Ruth et Blocher Christoph, 2004, "Réquérants logés dans les PC: Un provisoire qui dure", Editorial, Revue Vivre ensemble, ${ }^{\circ} 96$, https://asile.ch/2004/02/16/accueilrequerantsloges-dans-les-pcun-provisoire-qui-dure/, Consulté le 23 août 2017.

[10] Office Cantonal de la Statistique, 2009, «protection sociale à Genève : Résultats statistiques » Suisse, Genève.

[11] Parini Lorena, 1997, "La Suisse terre d'asile: un mythe ébranlé par l'histoire", Revue européenne des migrations internationales, vol.13, $\mathrm{n}^{\circ} 1$, p.51-69.

[12] République et canton de Genève, Département de Solidarité et d'Emploi, 2008, Directives cantonales en matière de prestations d'aide sociale aux requérants d'asile et statuts assimilés, Suisse, Genève.

[13] Schwab Myriam, 2000, «L'intégration non-intégrée. Analyse de l'installation durable des migrants sans documents », mémoire de licence, Département de travail social et politique sociales, Université de Fribourg.

[14] Togni Mario, 2009,"L'Hospice, baromètre d'une précarité de l'ombre" https://www.lecourrier.ch/_hospice_barometre_d_une_precarite_de_1_ombre, Consulté le 22 août 2017.

[15] UNHCR, 2015, Bienvenue ! 34 auteurs pour les réfugiés, Paris, Points.

[16] Vanistendael Stefan, 2009, Droits de l'enfant et résilience : deux approches qui s'enrichissent mutuellement, Bruxelles, Bureau International Catholique de l'Enfance.

[17] Weiss Pierre, 2004, «Pétition concernant la politique d'asile», Rapport de la Majorité, Suisse Genève.

\section{Annexe}

\section{Map Showing Petit-Saconnex}

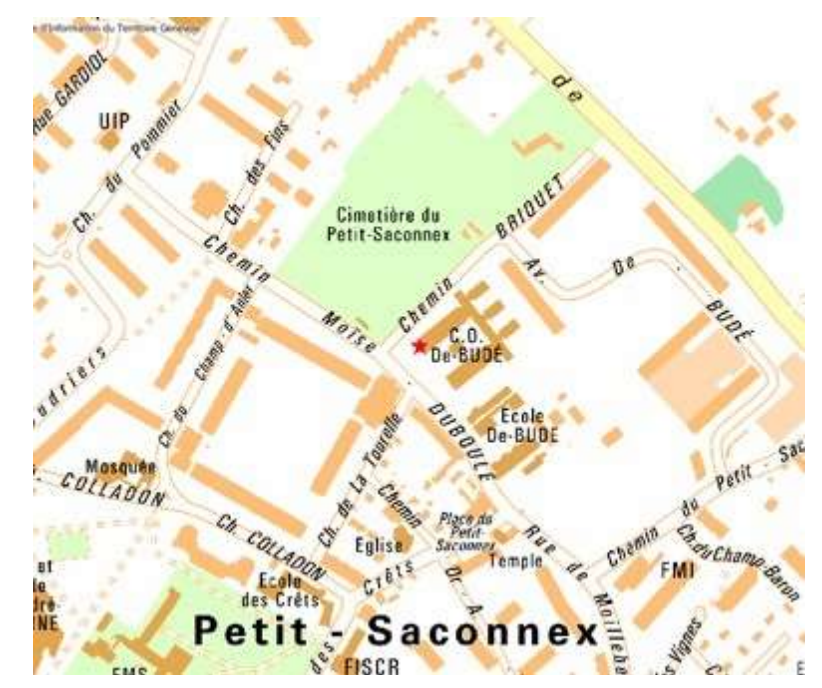

Source: web.me.com/.../Shapeimage_1.jpg

Citation: Timothée Codjo TOGBE. "Social Construct of Precariousness among the Refugees in the General Hospice of Geneva." International Journal of Research in Sociology and Anthropology (IJRSA), vol 3, no. 3, 2017, pp. 44-52. doi:http://dx.doi.org/10.20431/2454-8677.0303005.

Copyright: ( 2017 Authors. This is an open-access article distributed under the terms of the Creative Commons Attribution License, which permits unrestricted use, distribution, and reproduction in any medium, provided the original author and source are credited. 